\title{
A sex difference in the cortisol response to tail docking and ACTH develops between 1 and 8 weeks of age in lambs
}

\author{
A I Turner, B J Hosking ${ }^{1, *}$, R A Parr ${ }^{2, \dagger}$ and A J Tilbrook \\ Department of Physiology, PO Box 13F, Monash University, Victoria 3800, Australia \\ ${ }^{1}$ Animal Production, School of Agriculture and Forestry, University of Melbourne, Parkville, Victoria 3052, Australia \\ ${ }^{2}$ Victorian Institute of Animal Science, Werribee, Victoria 3030, Australia \\ (Requests for offprints should be addressed to A I Turner; Email: anne.turner@med.monash.edu.au) \\ ${ }^{*} \mathrm{~B}$ J H is now at Better Blend Stockfeeds Ptd Ltd, PO Box 21, Oakey, Queensland 4401, Australia \\ ${ }^{\dagger} \mathrm{R} A \mathrm{P}$ is now deceased
}

\begin{abstract}
It is important to understand factors that may influence responses to stress, as these factors may also influence vulnerability to pathologies that can develop when stress responses are excessive or prolonged. It is clear that, in adults, the sex of an individual can influence the cortisol response to stress in a stressor specific manner. Nevertheless, the stage of development at which these sex differences emerge is unknown. We tested the hypothesis that there are sex differences in the cortisol response to tail docking and ACTH in lambs of 1 and 8 weeks of age. We also established cortisol responses in males when tail docking was imposed alone and in combination with castration at these ages. In experiment 1, 1 and 8 week old male and female lambs were subjected to sham handling,
\end{abstract}

tail docking or, in males, a combination of tail docking and castration. In experiment 2 , we administered ACTH $(1.0 \mathrm{IU} / \mathrm{kg})$ to male and female lambs at 1 and 8 weeks of age. There were significant cortisol responses to all treatments at both ages. Sex differences in the cortisol responses to tail docking and ACTH developed between 1 and 8 weeks of age, with females having greater responses than males. The data suggest that the mechanism for the sex difference in response to tail docking may involve the adrenal glands. At both ages, in males, the cortisol response to the combined treatment of tail docking and castration was significantly greater than that for tail docking alone.

Journal of Endocrinology (2006) 188, 443-449

\section{Introduction}

Since excessive or prolonged responses to stress can lead to pathologies of physiological systems, it is important to understand factors that may influence responses to stress. It appears that the sex of an individual is one such factor. There are differences between the sexes in adult sheep in the cortisol response to stress and it appears that the type of stressor imposed influences the nature of these differences. For instance, females have been found to have a greater cortisol response than males to isolation-restraint stress (Turner et al. 2002a) and to an audiovisual stress that involved exposure to a barking dog (Turner et al. 2002b). In contrast, males have a greater cortisol response than females to insulin-induced hypoglycaemia (Turner et al. 2002a). While the mechanism for these sex differences is not clear, in vitro studies have found differences between the sexes at each level of the hypothalamo-pituitary adrenal axis (Canny et al. 1999), thus suggesting that the differences may arise at any level of this axis. However, we found no difference between the sexes in the cortisol response to injection of $\mathrm{ACTH}$ in adult sheep, suggesting that the mechanism for the sex differences in response to stress is at the level of the hypothalamo-pituitary unit rather than at the level of the adrenal gland (Turner et al. 2002a). Our recent study provided an anatomical basis for these differences arising within the hypothalamopituitary unit by showing that there were differences between the sexes in the distribution and co-localisation of corticotrophin-releasing hormone and arginine vasopressin in the paraventricular nucleus of sheep (Rivalland et al. 2005).

Although great progress has been made in our knowledge regarding the differences between the sexes in the stress-induced activity of the hypothalamo-pituitary adrenal axis in adult sheep, the stage of development at which these sex differences emerge is not known. For instance, we do not know if such sex differences exist in pre-pubertal, neonatal or fetal life, and if they do, what the nature of such sex differences is.

It has been shown that the hypothalamo-pituitary adrenal axis in sheep becomes functional during fetal life 
(Brooks et al. 1992, McMillen et al. 1995, Matthews \& Challis 1996, Reperant \& Durand 1997, Challis et al. 2001). A steady increase in circulating concentrations of cortisol towards the end of gestation has an important role in the maturation of the fetal organ systems and in triggering parturition (Matthews \& Challis 1996, Reperant \& Durand 1997, Challis et al. 2001). It is also clear that the fetal hypothalamo-pituitary adrenal axis is capable of responding to acute stress during late gestation. For example, fetal plasma concentrations of cortisol were elevated following haemorrhage (Rose et al. 1978), hypotension (Wood et al. 1982), hypoxia (Giussani et al. 1994) and hypoxemia (Gardner et al. 2001). Nevertheless, it is not known if cortisol responses to stress that occur during fetal life differ between the sexes. It was shown in fetal twins that consisted of a fetus of each sex that the pre-partum surge in plasma concentrations of cortisol occurred earlier in the male twin than in the female twin (Schwartz \& Rose 1998, Edwards \& McMillen 2002) and in singleton fetuses ACTH, but not cortisol, was higher in male fetuses than in females fetuses during late gestation (Edwards \& McMillen 2002). Nevertheless, it remains unclear whether the cortisol responses to stress differ between the sexes during fetal life.

It has also been shown that the hypothalamo-pituitary adrenal axis of lambs is capable of responding to stress during neonatal life. For instance, cortisol was elevated following restraint stress in lambs (of unspecified sex) at $0,0 \cdot 5,1,2,3$ and 4 weeks of age (Moberg et al. 1980), following open field testing in female lambs at $0,0 \cdot 5,2$ and 4 weeks of age (Moberg et al. 1980), following tail docking using rubber rings or hot or cold knife in lambs (mixed sex groups) at 3-5 weeks of age (Morris et al. 1994) and following surgical tail docking of female lambs or surgical tail docking and castration of male lambs at 3-6 weeks of age (Shutt et al. 1988). Cortisol was also elevated following injection of ACTH (1 IU) in lambs (of unspecified sex) at $0,0 \cdot 5,1,2,3$ and 4 weeks of age (Moberg et al. 1980). Nevertheless, it is not clear if male and female lambs responded differently to any of these treatments, since no sex comparisons were made. While cortisol concentrations were compared between male and female lambs following transport stress at 11 weeks of age (Horton et al. 1991), the cortisol measurements did not commence until after the hypothalamo-pituitary adrenal axis response to the stress would be expected to have finished (i.e. until $4 \mathrm{~h}$ after the completion of shipping). Thus, the stage of development at which sex differences emerge in the hypothalamo-pituitary adrenal axis response to stress remains elusive.

In this study, we measured the cortisol response to stress and ACTH in male and female lambs of 1 and 8 weeks of age. We used tail docking as the stressor, as this is a severe stressor that lambs of these ages may encounter as a part of routine husbandry. Thus, we tested the hypothesis that there are sex differences in the cortisol response to tail docking and ACTH in lambs of 1 and 8 weeks of age. Furthermore, since our studies with different stressors in adult sheep also suggest that the magnitude of the cortisol response is proportional to the severity of the stressor encountered (Turner et al. 2002a, 2002b), we also established cortisol responses in males when tail docking was imposed alone or in combination with castration at 1 and 8 weeks of age. Castration is another severe stressor that male lambs of these ages may encounter as a part of routine husbandry.

\section{Materials and Methods}

\section{Animals}

Border Leicester $\times$ Merino lambs were used in this study. Two days prior to an experiment day, lambs and their dams were brought in from pasture and placed in outdoor pens. Each pen included lambs from each treatment. On the same day, indwelling jugular catheters (angiocaths) were inserted in all lambs. Water was available ad libitum throughout the experiment. A standard maintenance ration was provided for dams.

This study conformed with the requirements of the Australian Prevention of Cruelty to Animals Act 1986 and was conducted in accordance with the NHMRC/ CSIRO/ACC Australian Code of Practice for the Care and Use of Animals for Scientific Purposes. The Animal Experimentation Ethics Committee of the Victorian Institute of Animal Science approved all procedures used in this study.

\section{Experimental procedure}

Experiment 1 Week old male $(n=30)$ and female $(n=20)$ lambs and 8 week old male $(n=30)$ and female $(n=20)$ lambs were used in this study. Lambs of each age were allocated to the following treatments ( $n=10 /$ group): sham handled males, sham handled females, tail docked males, tail docked females, tail docked and castrated males. Blood samples $(3 \mathrm{ml})$ were collected $-60,-45,-30,-15$, $0,5,10,20,30,45,60,75,90,105,120,135,150,165$, 180, 200, 220 and $240 \mathrm{~min}$ and 24 and $48 \mathrm{~h}$ relative to the imposition of the relevant treatment. Tail docking involved applying an Elastrator rubber marking ring (Allhank Trading Company, South Melbourne, Australia) to the tail using a specialised applicator (Allhank Trading Company). For castration, the Elastrator rubber ring was applied to the scrotum proximal to the testes. Consistent with normal industry practice, anaesthetic and/or analgesic treatments were not administered. Sham handled males and females were handled as though the rubber tail docking/castration rings were applied but no rings were applied. Mean ( \pm S.E.M.) body weight was $7 \cdot 0 \pm 0 \cdot 2 \mathrm{~kg}$ for week old lambs and $13 \cdot 8 \pm 0 \cdot 5 \mathrm{~kg}$ for 8 week old lambs. 
Body weight did not differ significantly between the sexes in lambs of either age. Concentrations of cortisol were measured in plasma harvested from all blood samples.

Experiment 2 Male $(n=10)$ and female $(n=10)$ lambs were used in this study. At 1 week of age, all lambs were given an intravenous injection of ACTH $(1 \cdot 0 \mathrm{IU} / \mathrm{kg})$ and blood samples ( $3 \mathrm{ml}$ ) were collected $0,15,30,60,90,120$, 180, $240 \mathrm{~min}$ after the injection. This procedure was repeated when the lambs were 8 weeks old. Mean ( \pm S.E.M.) body weight was $7 \cdot 2 \pm 0 \cdot 3 \mathrm{~kg}$ at 1 week of age and $18.4 \pm 0.6 \mathrm{~kg}$ at 8 weeks of age. Bodyweight did not differ significantly between the sexes at either age. Concentrations of cortisol were measured in plasma harvested from all blood samples.

\section{Cortisol radioimmunoassay}

Total plasma concentrations of cortisol were measured using a cortisol radioimmunoassay kit (Coat-A-Count, Diagnostic Products Corporation, CA, USA). Twentyfour assays were conducted for Experiment 1 and four assays were conducted for Experiment 2. The minimum detectable concentration was $2.5 \mathrm{ng} / \mathrm{ml}$ and the interassay coefficient of variation was $8 \cdot 3 \%$ at $59 \cdot 3 \mathrm{ng} / \mathrm{ml}$.

\section{Statistical analyses}

Experiment 1 Pre-treatment plasma concentrations of cortisol were defined as the mean of all concentrations prior to treatment (i.e. time $=-60,-45,-30$ and -15 min relative to treatment). Pre-treatment plasma concentrations of cortisol were compared using analysis of variance in 2 separate analyses. For males and females subjected to tail docking, age, sex and treatment were between-subject factors. The variance of these data became homogeneous after square root transformation. For males subjected to tail docking or tail docking combined with castration, age and treatment were between-subject factors. The variance of these data was homogeneous, thus, no transformation was performed. Post hoc comparisons were made, where appropriate, using least significant differences.

Plasma concentrations of cortisol were compared using repeated measures analysis of variance. For males and females subjected to tail docking, the within-subject factor was time and the between-subject factors were age, sex and treatment. For males subjected to tail docking or tail docking combined with castration, the within-subject factor was time and the between-subject factors were age and treatment. The variance of both data sets was homogeneous. Post hoc comparisons were made, where appropriate, using least significant differences.

Experiment 2 Plasma concentrations of cortisol were compared using repeated measures analysis of variance.
Table 1 Mean \pm S.E.M. pre-treatment plasma concentrations of cortisol $(\mathrm{ng} / \mathrm{ml})$ in experiment 1 for 1 and 8 week old males and females that underwent sham handling or tail docking and in 1 and 8 week old males that underwent tail docking and castration

\begin{tabular}{|c|c|c|}
\hline & Males & Females \\
\hline \multicolumn{3}{|l|}{1 week old } \\
\hline Sham handling & $39 \cdot 4 \pm 4 \cdot 6$ & $36 \cdot 6 \pm 3 \cdot 3$ \\
\hline Tail docking & $34 \cdot 9 \pm 3 \cdot 8$ & $33 \cdot 3 \pm 3 \cdot 2$ \\
\hline Tail docking and castration & $38 \cdot 0 \pm 9 \cdot 5$ & \\
\hline \multicolumn{3}{|l|}{8 week old } \\
\hline Sham handling & $35 \cdot 4 \pm 3 \cdot 9$ & $50 \cdot 6 \pm 6 \cdot 9^{*}$ \\
\hline Tail docking & $54 \cdot 5 \pm 9 \cdot 4$ & $38 \cdot 3 \pm 4 \cdot 1$ \\
\hline Tail docking and castration & $43 \cdot 6 \pm 7 \cdot 1$ & \\
\hline
\end{tabular}

The within-subject factors were age and time, and the between-subject factor was sex. The variance of the data was homogeneous. Post hoc comparisons were made, where appropriate, using least significant differences.

\section{Results}

\section{Experiment 1}

Pre-treatment cortisol Pre-treatment plasma concentrations of cortisol were significantly $(P<0 \cdot 05)$ higher in 8 week old sham handled females compared with 8 week old sham handled males (Table 1). Due to this significant variability in pre-treatment data, plasma concentrations of cortisol are represented in Figures 1 and 2 in both $\mathrm{ng} / \mathrm{ml}$ and as a percentage of pre-treatment concentrations. Statistical analyses were conducted using the data that were expressed as a percentage of pre-treatment. There were no other significant differences between the sexes in pre-treatment plasma concentrations of cortisol. Pretreatment plasma concentrations of cortisol did not differ significantly between the three treatments imposed on males at 1 or 8 weeks of age.

\section{Males and females exposed to sham handling or tail docking}

Response to sham handling In week old females, plasma concentrations of cortisol became significantly $(P<0 \cdot 05)$ elevated above pre-treatment concentrations $20 \mathrm{~min}$ after the commencement of sham handling (Fig. 1). There was no significant elevation of plasma concentrations of cortisol following sham handling in week old males. In 8 week old lambs, plasma concentrations of cortisol became significantly elevated $(P<0 \cdot 05)$ above pre-treatment concentrations in males from $0-20 \mathrm{~min}$ and in females from 0-30 min after the commencement of sham handling. 


\section{One week old}

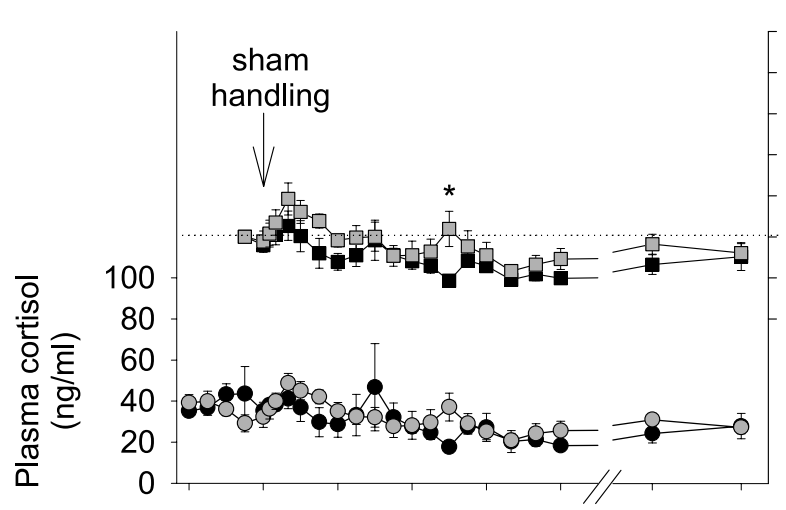

Eight weeks old sham

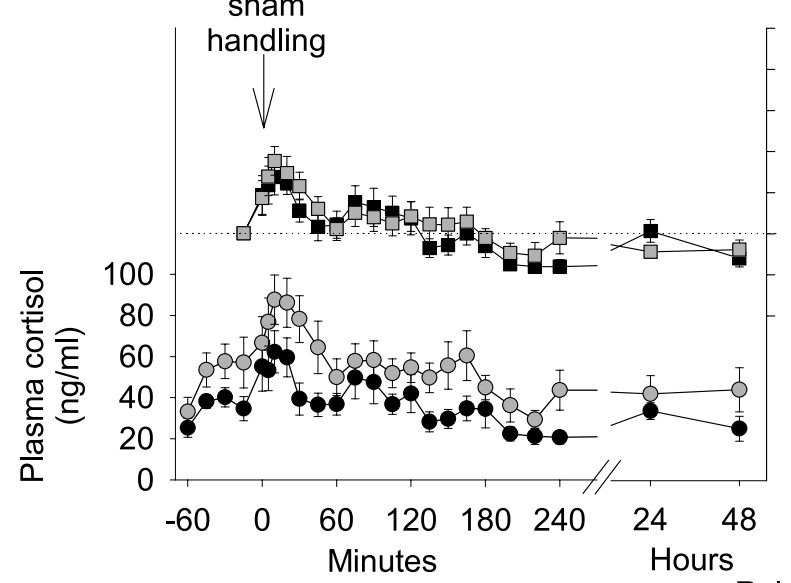

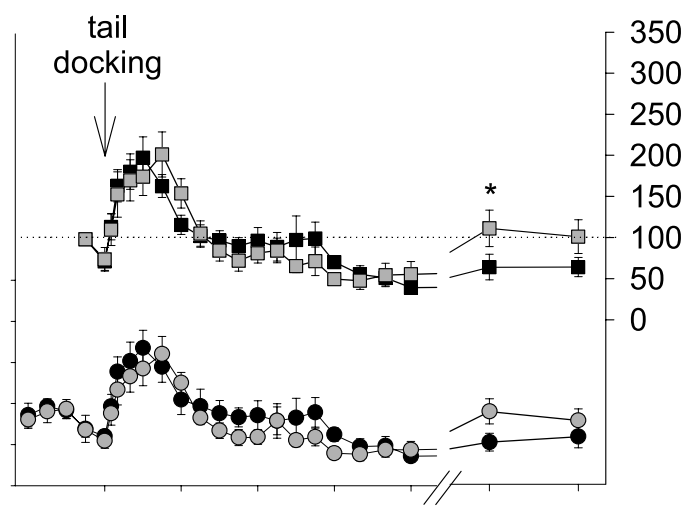

350

300

250

200

150

100

50

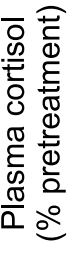

Relative to treatment
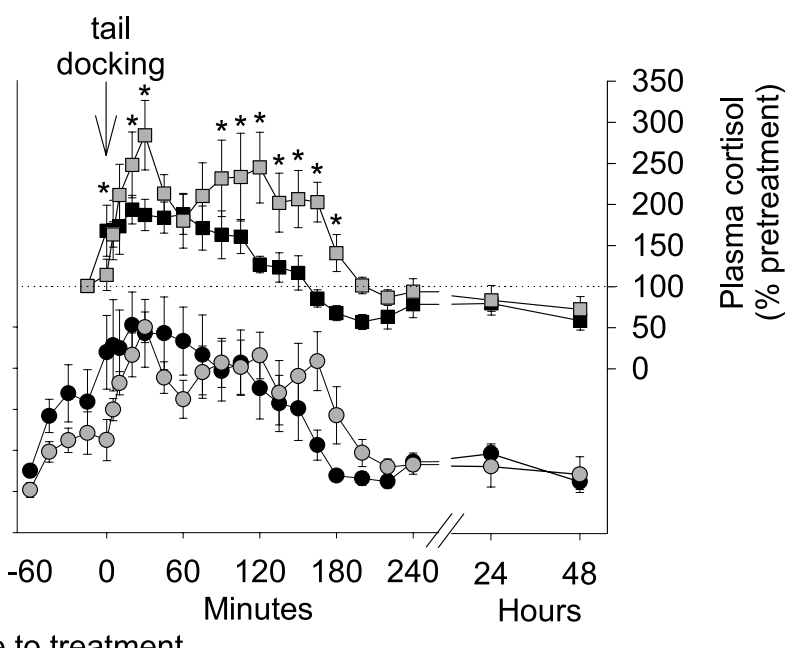

Figure 1 Mean ( \pm S.E.M.) plasma concentrations of cortisol $(\mathrm{ng} / \mathrm{ml}$; left-hand axes) in male $\boldsymbol{\bullet}$ and female $\bigcirc$ lambs and mean $( \pm$ S.E.M.) plasma concentrations of cortisol as a percentage of pre-treatment concentrations (\% pretreat; right-hand axes) in male $\mathbf{\square}$ and female $\square$ lambs in Experiment 1. The concentrations shown are from - 60 to $240 \mathrm{~min}$ and at 24 and $48 \mathrm{~h}$ after sham handling (panels at left) and after the application of Elastrator tail docking rings (panels at right) in lambs that were 1 week old (upper panels) and 8 weeks old (lower panels). ${ }^{*}$ Indicates a significant $(P<0 \cdot 05)$ difference between sexes.

Response to tail docking In week old lambs, plasma concentrations of cortisol became significantly elevated $(P<0 \cdot 05)$ above pre-treatment concentrations in males from 10 $45 \mathrm{~min}$ and in females from 10-60 min after the application of the Elastrator tail docking rings. In 8 week old lambs, plasma concentrations of cortisol became significantly elevated $(P<0 \cdot 05)$ above pre-treatment concentrations in males from $0-105 \mathrm{~min}$ and in females from 5-165 min after the application of the tail docking rings.

Sex comparisons In lambs that were 1 week old, the only significant differences between the sexes in the plasma concentrations of cortisol were at $150 \mathrm{~min}$ after sham handling and at $24 \mathrm{~h}$ after tail docking. In both cases, plasma concentrations were significantly higher $(P<0 \cdot 05)$ in females than in males (Fig. 1). In 8 week old lambs that were sham handled, there were no significant differences between the sexes in plasma concentrations of cortisol. In contrast, in 8 week old lambs, plasma concentrations of cortisol were significantly higher $(P<0 \cdot 05)$ in females than in males from 20-30 min and from 90-180 min after the application of tail docking rings. At time $=0 \mathrm{~min}$, plasma concentrations of cortisol were higher $(P<0.05)$ in males than in females.

Age comparisons Plasma concentrations of cortisol were significantly higher $(P<0 \cdot 05)$ in 8 week old lambs than in week old lambs (Fig. 1) in sham handled males (time $=0-10,75$ and $105-120 \mathrm{~min}$ ), sham handled females (time $=0-10$ and $120 \mathrm{~min}$ ), tail docked males (time $=0-5$ and 60-105 $\mathrm{min}$ ) and tail docked females (time $=5-30$ and 75-200 min). 


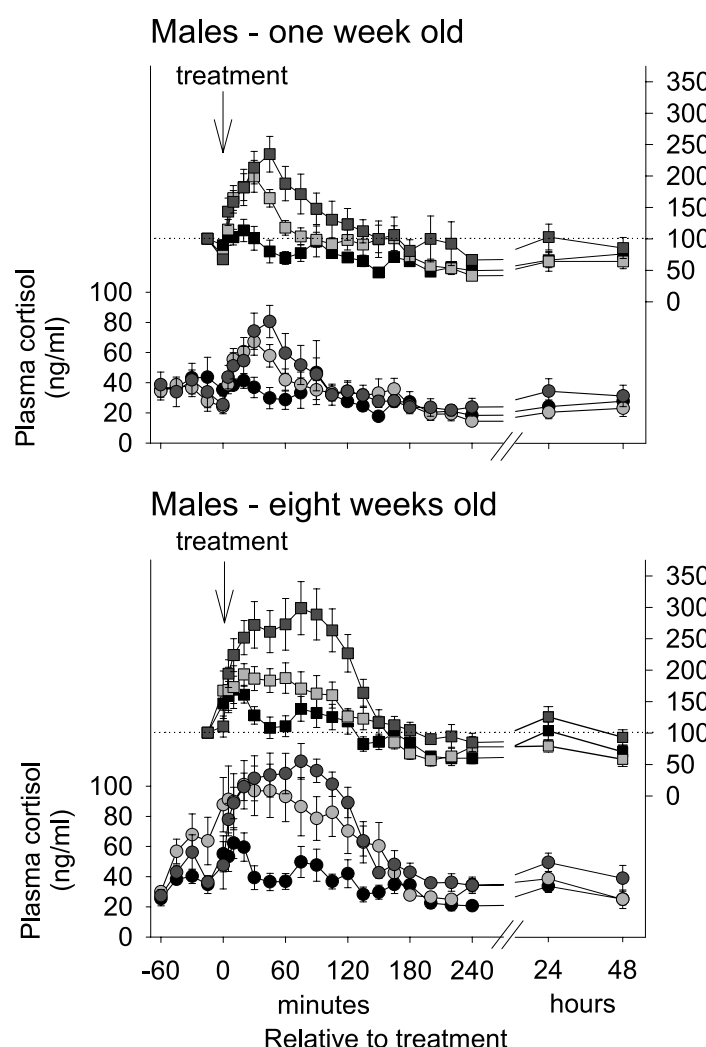

Figure 2 Mean ( \pm s.E.M.) plasma concentrations of cortisol $(\mathrm{ng} / \mathrm{ml}$; left-hand axes) in male lambs that were sham handled $\bullet$, tail docked or tail docked and castrated and mean ( \pm S.E.M.) plasma concentrations of cortisol as a percentage of pre-treatment concentrations (\% pretreat; right-hand axes) in male lambs that were sham handled $\boldsymbol{\square}$, tail docked $\square$ or tail docked and castrated $\square$ in Experiment 1. The concentrations shown are from -60 to $240 \mathrm{~min}$ and at 24 and $48 \mathrm{~h}$ after treatment in lambs that were 1 week old (upper panels) and 8 weeks old (lower panels).

Significant differences are described in the text.

Males exposed to sham handling, tail docking or tail docking and castration At both ages, the combined treatment of tail docking and castration elicited a greater cortisol response than tail docking alone (Fig. 2). Plasma concentrations of cortisol were significantly greater $(P<0 \cdot 05)$ in males that underwent the combined treatment compared with those that underwent only tail docking 30-120 and 200-220 $\mathrm{min}$ and $24 \mathrm{~h}$ after the imposition of the treatments (at both ages).

\section{Experiment 2}

Response to ACTH In week old males and females and in 8 week old males, plasma concentrations of cortisol were significantly higher $(P<0 \cdot 05)$ than concentrations at time $=$ $0 \mathrm{~min}$ from 15-120 min after injection of ACTH (Fig. 3). In 8 week old females, plasma concentrations of cortisol were significantly higher $(P<0 \cdot 05)$ than concentrations at time $=0 \mathrm{~min}$ from $15-180 \mathrm{~min}$.

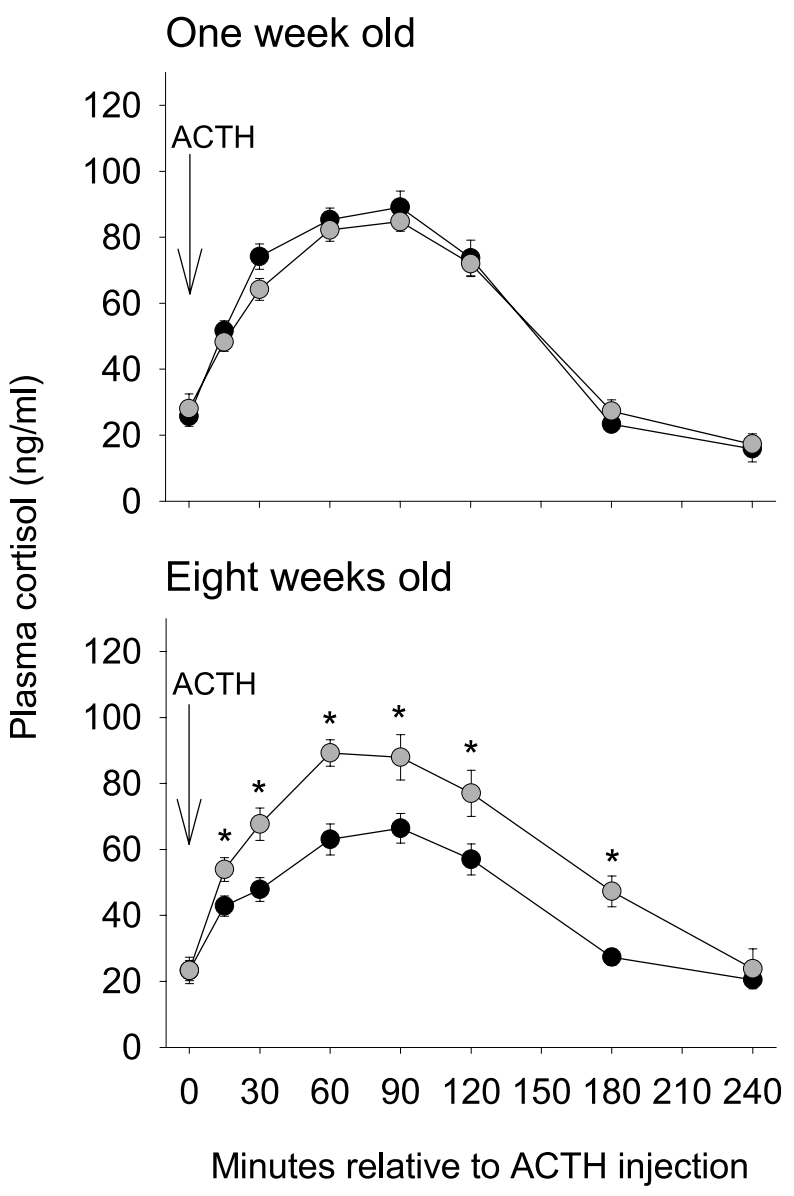

Figure 3 Mean ( \pm S.E.M.) plasma concentrations of cortisol $(\mathrm{ng} / \mathrm{ml})$ in male and female lambs in Experiment 2 from 0 to $240 \mathrm{~min}$ after injection of ACTH $(1.0 \mathrm{IU} / \mathrm{kg})$ at 1 week of age (upper panel) and 8 weeks of age (lower panel). * Indicates a significant $(P<0 \cdot 05)$ difference between sexes.

Sex comparisons Plasma concentrations of cortisol did not differ significantly between males and females at 1 week of age. In contrast, at 8 weeks of age, plasma concentrations of cortisol were significantly greater $(P<0 \cdot 05)$ in females than males from 15-180 min after injection of ACTH (Fig. 3).

\section{Discussion}

These data suggest that the sex difference in the cortisol response to stress emerges between 1 and 8 weeks of age in sheep. At 8 weeks of age, the stressor imposed, tail docking, clearly invoked a greater cortisol response in females than in males. In this regard, it is similar to isolation-restraint stress (Turner et al. 2002a) and audiovisual stress (Turner et al. 2002b) in adult sheep but differs to insulin-induced hypoglycaemia (Turner et al. 2002a) in which it was the males that had a greater response than 
females. It is important to try to understand factors that may influence an individual's responses to stress, since factors that can influence responses to stress may also influence vulnerability to pathologies of physiological systems that can be induced when responses to stress are excessive or prolonged. While it is thought that the presence of sex steroids may be responsible for the sex differences in response to stress in rats (Handa et al. 1994), we have not found evidence for effects of circulating sex steroids on the cortisol response to stress in adult sheep (Tilbrook et al. 1999, Turner et al. 2002a). It is not known if sex steroids were involved in the sex differences seen in this study.

A sex difference in the cortisol response to ACTH also emerged between 1 and 8 weeks of age. Again, it was the females that had a greater cortisol response than the males. The existence of a sex difference in response to ACTH at 8 weeks of age is not consistent with our findings in adult sheep, in which we found no difference between the sexes in the cortisol response to treatment with ACTH (Turner et al. 2002a). It is not clear why such a difference was found at 8 weeks of age but not in adulthood. Nevertheless, this finding does fit with earlier findings that the adrenal glands were larger and the ACTH-induced cortisol production in cultures of adrenocortical cells was greater in female sheep compared with male sheep (Canny et al. 1999). The sex difference in the cortisol response to ACTH that we have found in lambs of 8 weeks of age indicates that the mechanism for the sex difference in the cortisol response to stress at this age may involve the adrenal glands.

The maturation of the hypothalamo-pituitary adrenal axis in sheep clearly occurs very early during development, with this axis being functional even before birth (Brooks et al. 1992, McMillen et al. 1995, Matthews \& Challis 1996, Reperant \& Durand 1997, Challis et al. 2001). Our results show that in both 1 and 8 week old male and female lambs the hypothalamo-pituitary adrenal axis was sufficiently mature to be capable of responding to the stress of tail docking, to treatment with ACTH and, in males, to the combined stress of tail docking and castration. Nevertheless, several of our findings suggest that the hypothalamo-pituitary adrenal axis undergoes further maturation between 1 and 8 weeks of age. For instance, the magnitude of the cortisol response to tail docking was not as great at 1 week of age as at 8 weeks of age and the sex differences in the cortisol responses to stress and ACTH emerged between 1 and 8 weeks of age. Nevertheless, our data in males exposed to tail docking alone or in combination with castration showed that even at 1 week of age, the hypothalamo-pituitary adrenal axis was capable of mounting a cortisol response that was proportional to the severity of the stressor. The data showed that, at both 1 and 8 weeks of age, the cortisol response to the combined treatment was significantly greater than when tail docking alone was imposed. It is not likely that the higher response in the combined treatment was associated with the removal of testicular factors from the circulation in castrated males because there is no evidence in sheep that testicular status influences the activity of the hypothalamo-pituitary adrenal axis. This has been demonstrated in vivo (Tilbrook et al. 1999) and in vitro (Canny et al. 1999). Collectively, our data show that, while the hypothalamo-pituitary adrenal axis is highly functional at 1 week of age, it appears that it may mature further by 8 weeks of age.

It is not clear why pre-treatment plasma concentrations of cortisol were significantly higher in females than in males in the sham handling treatment at 8 weeks of age. This result appears to be spurious, particularly as, in 8 week old lambs that were later tail docked, the difference in pre-treatment plasma concentrations of cortisol, while not significant, was in the opposite direction (i.e. males had greater concentrations than females). It is not possible that there were differences in the pre-treatment environment or husbandry of lambs in the different groups since each of the experimental pens contained lambs from each treatment. Once before, we also found significant differences between groups in the pre-treatment plasma concentrations of cortisol for no apparent reason (Turner et al. 2002a). Our earlier study consisted of three experiments. Gonadectomised animals were found to have pretreatment plasma concentrations of cortisol that were significantly higher than those of gonad intact animals in two experiments and significantly lower than those of gonad intact animals in the third experiment (Turner et al. 2002a). Nevertheless, by expressing our data as a percentage of pre-treatment, we were able to investigate the responses to stress which were the focus of this study.

In conclusion, these data showed that a sex difference in the cortisol response to tail docking and ACTH developed between 1 and 8 weeks of age in lambs. The data suggest that the mechanism for the sex difference in the response to tail docking at 8 weeks of age may involve the adrenal glands.

\section{Acknowledgements}

We thank the support staff of the Victorian Institute of Animal Science Physiology Section and Michelle Ibbott for their assistance.

\section{Funding}

This work was funded by the Victorian Institute of Animal Science, the University of Melbourne and Monash University. The authors declare that there is no conflict of interest that would prejudice the impartiality of this scientific work. 


\section{References}

Brooks AN, Currie IS, Gibson F \& Thomas GB 1992

Neuroendocrine regulation of sheep fetuses. Reproduction Supplement 45 69-84.

Canny BJ, O'Farrell KA, Clarke IJ \& Tilbrook AJ 1999 The influence of sex and gonadectomy on the hypothalamo-pituitary-adrenal axis of the sheep. Journal of Endocrinology 162 215-225.

Challis JRG, Sloboda D, Matthews SG, Holloway A, Alfaidy N, Patel FA, Whittle W, Fraser M, Moss TJM \& Newnham J 2001 The fetal placental hypothalamic-pituitary-adrenal (HPA) axis, parturition and post natal health. Molecular and Cellular Endocrinology 185 135-144.

Edwards LJ \& McMillen IC 2002 Impact of maternal undernutrition during the periconceptional period, fetal number, and fetal sex on the development of the hypothalamo-pituitary adrenal axis in sheep during late gestation. Biology of Reproduction 66 1562-1569.

Gardner DS, Fletcher AJW, Fowden AL \& Giussani DA 2001 Plasma adrenocorticotropin and cortisol concentrations during acute hypoxemia after a reversible period of adverse intrauterine conditions in the ovine fetus during late gestation. Endocrinology 142 589-598.

Giussani DA, McGarrigle HHG, Moore PJ, Bennet L, Spencer JAD \& Hanson MA 1994 Carotid-sinus nerve-section and the increase in plasma-cortisol during acute-hypoxia in fetal sheep. Journal of Physiology - London 477 75-80.

Handa RJ, Burgess LH, Kerr JE \& O'Keefe JA 1994 Gonadal steroid hormone receptors and sex differences in the hypothalamo-pituitary -adrenal axis. Hormones and Behavior 28 464-476.

Horton GMJ, Malinowski K, Burgher CC \& Palatini DD 1991 The effect of space allowance and sex on blood catecholamines and cortisol, feed consumption and average daily gain in growing lambs. Applied Animal Behaviour Science 32 197-204.

Matthews SG \& Challis JRG 1996 Regulation of the hypothalamopituitary-adrenocortical axis in fetal sheep. Trends in Endocrinology and Metabolism 7 239-246.

McMillen IC, Phillips ID, Ross JT, Robinson JS \& Owens JA 1995 Chronic stress - the key to parturition. Reproduction Fertility and Development 7 499-507.

Moberg GP, Anderson CO \& Underwood TR 1980 Ontogeny of the adrenal and behavioral-responses of lambs to emotional-stress. Journal of Animal Science 51 138-142.
Morris DG, Kuchel TR \& Maddocks S 1994 Stress responses in lambs to different tail docking methods. Proceedings of the Australian Society of Animal Production 20 202-205.

Reperant EN \& Durand P 1997 The development of the ovine fetal adrenal gland and its regulation. Reproduction Nutrition Development 37 81-95.

Rivalland ETA, Iqbal J, Clarke IJ, Turner AI \& Tilbrook AJ 2005 Co-localization and distribution of corticotrophin-releasing hormone, arginine vasopressin and enkephalin in the paraventricular nucleus of sheep: a sex comparison. Neuroscience $132755-766$.

Rose JC, Macdonald AA, Heymann MA \& Rudolph AM 1978 Developmental aspects of pituitary-adrenal axis response to hemorrhagic stress in lamb fetuses in utero. Journal of Clinical Investigation 61 424-432.

Schwartz J \& Rose JC 1998 Development of the pituitary adrenal axis in fetal sheep twins. American Journal of Physiology-Regulatory Integrative and Comparative Physiology $43 \mathrm{R} 1-\mathrm{R} 8$.

Shutt DA, Fell LR, Connell R \& Bell AK 1988 Stress responses in lambs docked and castrated surgically or by the application of rubber rings. Australian Veterinary Journal 65 5-7.

Tilbrook AJ, Canny BJ, Serapiglia MD, Ambrose TJ \& Clarke IJ 1999 Suppression of the secretion of luteinizing hormone due to isolation/restraint stress in gonadectomised rams and ewes is influenced by sex steroids. Journal of Endocrinology 160 469-481.

Turner AI, Canny BJ, Hobbs RJ, Bond JD, Clarke IJ \& Tilbrook AJ $2002 a$ Influence of sex and gonadal status of sheep on cortisol secretion in response to ACTH and on cortisol and LH secretion in response to stress: importance of different stressors. Journal of Endocrinology 173 113-121.

Turner AI, Rivalland ETA, Clarke IJ, Lambert GW, Morris MJ \& Tilbrook AJ $2002 b$ Noradrenaline, but not neuropeptide Y, is elevated in cerebrospinal fluid from the third cerebral ventricle following audiovisual stress in gonadectomised rams and ewes. Neuroendocrinology 76 373-380.

Wood CE, Keil LC \& Rudolph AM 1982 Hormonal and hemodynamic-responses to vena-caval obstruction in fetal sheep. American Journal of Physiology 243 E278-E286.

Received 27 July 2005

Accepted 16 November 2005 